\title{
Pengaruh Molaritas dalam Teknik Spray terhadap Performa Fotodetektor Berbasis ZnO
}

\author{
Okky Fajar Tri Maryana ${ }^{(1, a)^{*}}$, Anisa Fitri ${ }^{(1)}$, Mohamad Samsul Anrokhi ${ }^{(1)}$, \\ Wahyu Solafide Sipatuhar ${ }^{(2)}$, dan Eka Nurfani( ${ }^{(2)}$ \\ ${ }^{(1)}$ Program Studi Fisika, Institut Teknologi Sumatera, Lampung, Indonesia \\ ${ }^{(2)}$ Program Studi Teknik Material, Institut Teknologi Sumatera, Lampung, Indonesia \\ Email : ${ }^{\left(a^{*}\right)}$ okky.trimaryana@fi.itera.ac.id, ${ }^{(1)}$ anisa.11116026@student.itera.ac.id, ${ }^{(1)}$ anrokhi@fi.itera.ac.id \\ ${ }^{(2)}$ wahyu.sipahutar@mt.itera.ac.id, ${ }^{(2)}$ eka.nurfani@mt.itera.ac.id
}

Diterima (20 November 2020), Direvisi (13 Januari 2021)

\begin{abstract}
ZnO:Fe thin films has been successfully carried out by a simple spray pyrolysis method. The thin film was grown on ITO (Indium Tin Oxide) substrate with a metal-semiconductor-metal (MSM) structure. ZnO:Fe thin film characters as photodetector application include morphological structure, and electrical properties. SEM image results show the molarity difference can affect the particle size. The Current-Voltage (I-V) characterization shows that different solvent effects and molarity give different sensitivity. Sample ZnO:Fe $0.5 \mathrm{M}$ Ethanol has the highest sensitivity compared to other samples because it has a fairly low current and high bright current.
\end{abstract}

Keywords: Thin films, molarity, spray pyrolysis, , ZnO:Fe

\begin{abstract}
Abstrak. Film tipis $\mathrm{ZnO}$ yang didoping $\mathrm{Fe}(\mathrm{ZnO}: \mathrm{Fe})$ telah berhasil dilakukan dengan metode spray pyrolysis sederhana. Film tipis ditumbuhkan pada substrat ITO (Indium Tin Oxide) dengan struktur metalsemiconductor-metal (MSM). Karakteristik film tipis $\mathrm{ZnO}$ :Fe sebagai fotodetektor meliputi struktur morfologi dan sifat listrik. Hasil citra scanning electron microscopy (SEM) menunjukkan bahwa beda molaritas dapat mempengaruhi ukuran partikel. Karakterisasi arus-tegangan (I-V) menunjukkan bahwa efek molaritas yang berbeda menghasilkan sensitivitas yang berbeda yang berbeda. Sampel ZnO:Fe 0,5 M Etanol memiliki sensitivitas tertinggi dibandingkan sampel lain karena memiliki arus gelap cukup rendah dan arus terang yang tinggi.
\end{abstract}

Kata kunci: film tipis, molaritas, spray pyrolisis, ZnO:Fe

\section{PENDAHULUAN}

Penelitian tentang lapisan tipis berukuran nano seperti $\mathrm{In}_{2} \mathrm{O}_{3}, \mathrm{WO}_{3}, \mathrm{SnO}_{2}$, $\mathrm{TiO}, \mathrm{ZnO}$ telah meningkat selama beberapa tahun terakhir [1]. Diantara materialmaterial tersebut, $\mathrm{ZnO}$ merupakan material baru yang memiliki beberapa keuntungan dibandingkan dengan material lain sebagai sel surya, sel fotovoltaik, atau material yang sesitif terhadap cahaya [2]. Karena energi ikatnya yang besar (60 meV), celah pita lebar $(3,37 \mathrm{eV})$ dan metode sintesis serta perakitan yang mudah, semikonduktor berbasis $\mathrm{ZnO}$ telah menjadi salah satu bahan paling populer untuk aplikasi listrik dan optik dari waktu ke waktu. Material bahan yang menjanjikan untuk aplikasi optoelektronik seperti laser ultraviolet, dioda pemancar cahaya, perangkat sambungan $\mathrm{p}-\mathrm{n}$, transistor film tipis, sel surya, perangkat akustik, sensor kimia dan 
biologi [1]. Untuk aplikasi elektroda transparan dan konduksi dalam sel surya dan transistor film tipis, pengembangan film $\mathrm{ZnO}$ dengan resistif rendah dan transparansi tinggi sangat penting.

Penelitian terkait film tipis $\mathrm{ZnO}: \mathrm{Fe}$ ini sudah pernah dilakukan sebelumnya oleh para peneliti [3]. Dalam penelitian ini, material film tipis $\mathrm{ZnO}$ doping $\mathrm{Fe}$ dibuat dengan metode spray pyrolysis dengan konsentrasi doping $\mathrm{Fe} 3 \%$ dan variasi molaritas yang ditumbuhkan pada substrat ITO (Indium Tin Oxide) dan didapatkan permasalahan dalam penelitian ini adalah variasi molaritas dapat mempengaruhi ukuran partikel sehingga perlu untuk dilakukan variasi molaritas [4]. Informasi karakterisasi morfologi dan listrik film tipis $\mathrm{ZnO}: \mathrm{Fe}$ yang didapatkan menjadi landasan untuk merancang detektor cahaya pada berbagai aplikasi industri di provinsi Lampung.

\section{METODE PENELITIAN}

Tahap perancangan metode diawali dengan menentukan material-material yang akan dijadikan prekursor untuk membuat film tipis dan penentuan konsentrasi dan persentase doping. Teknik penumbuhan yang digunakan untuk mendeposisikan film tipis $\mathrm{ZnO}$ adalah spray pyrolyisis dengan alat nanospray sederhana.

Spray pyrolysis adalah salah satu metode penumbuhan film tipis di mana dilakukan penyemprotan larutan sampai mengendap pada substrat yang telah dipanaskan, yang kemudian bereaksi untuk membentuk senyawa kimia [5]. Metode spray pyrolysis mampu menghasilkan partikel berbentuk bulat, tanpa aglomerasi, serta rentang waktu produksi yang sangat pendek (dapat kurang dari satu detik). Ukuran partikel yang dihasilkan juga dapat dikontrol dengan mudah melalui pengontrolan konsentrasi prekursor yang digunakan maupun ukuran droplet yang dihasilkan nebulizer. Komposisi kimiawi partikel yang disintesis juga mudah dikontrol melalui pengontrolan fraksi perbandingan molar masing-masing prekursor dalam larutan yang akan dispray. Variasi molar ditunjukkan pada Tabel 1.

Pada metode Spray Pyrolysis penelitian ini alat yang digunakan adalah nanospray. Nanospray adalah alat yang mampu mengubah partikel kecil ke skala nanometer. Alat ini memiliki kapasitas tangki $20 \mathrm{ml}$ dan memiliki daya atomizer minimal 0,2 atau $200 \mathrm{~nm}$. Harga alat tergolong murah dengan daya tahan tinggi sehingga mengurangi biaya penumbuhan film tipis. Jarak optimum spray alat ini sampai $15 \mathrm{~cm}$ pada temperatur ruang.

Pada metode spray pyrolysis terdapat beberapa parameter penting untuk mengontrol struktur dari film tipis diantaranya yaitu temperatur penumbuhan dan molaritas [6]. Di antara variabelvariabel tersebut, temperatur penumbuhan pada substrat telah dianggap sebagai faktor paling penting dalam memproduksi film tipis dari proses spray pyrolysis karena tetesan pengeringan, dekomposisi, kristalisasi, dan pertumbuhan butir sangat bergantung pada parameter tersebut [7].

Penumbuhan film tipis $\mathrm{ZnO}$ didoping dengan Fe dengan metode Spray Pyrolysis sederhana dipilih karena metode ini cukup mudah dilakukan, efisien waktu, dan ekonomis.

Tabel 1. Variasi Molaritas dari sampel yang dibuat.

\begin{tabular}{cc}
\hline Material & Molaritas (M) \\
\hline $\mathrm{ZnO}: \mathrm{Fe}$ & 0,01 \\
$\mathrm{ZnO}: \mathrm{Fe}$ & 0,05 \\
$\mathrm{ZnO}: \mathrm{Fe}$ & 0,10 \\
\hline
\end{tabular}


Selain suhu dapat dikontrol, pencampuran prekursor juga mudah dilakukan. Metode Spray Pyrolysis pada penelitian ini adalah yang metode paling sederhana yaitu dengan menggunakan alat nanospray yang telah dijual secara komersial. Langkah yang pertama yaitu menyiapkan nanospray, kemudian tuang prekursor ke dalam tabung nanospray. Semprotkan larutan pada substrat yang diletakkan di atas hotplate yang sudah dipanaskan dengan suhu $450^{\circ} \mathrm{C}$. Setelah waktu deposisi 15 detik matikan nanospray, kemudian turunkan suhu hot plate hingga suhu ruang, dan simpan film tipis pada kertas perkamen yang bersih. Waktu yang sangat singkat ini merupakan keunggulan dari teknik yang dipilih, seperti yang sudah dilaporkan pada penelitian sebelumnya $[2,3]$.

Untuk pengukuran arus-tegangan (I-V), sampel diuji dengan rangkaian seri menggunakan amperemeter (Fluke 8808A) dan sumber tegangan (UTP 3305C programmable DC power supply) sebagai sumber tegangan. Skema pengukuran (I-V) ditujukkkan pada Gambar 1. Pasta perak (Ag) dengan jarak 2 mm digunakan sebagai kontak elektroda dengan lapisan tipis sehingga membentuk persambungan metalsemikonduktor.

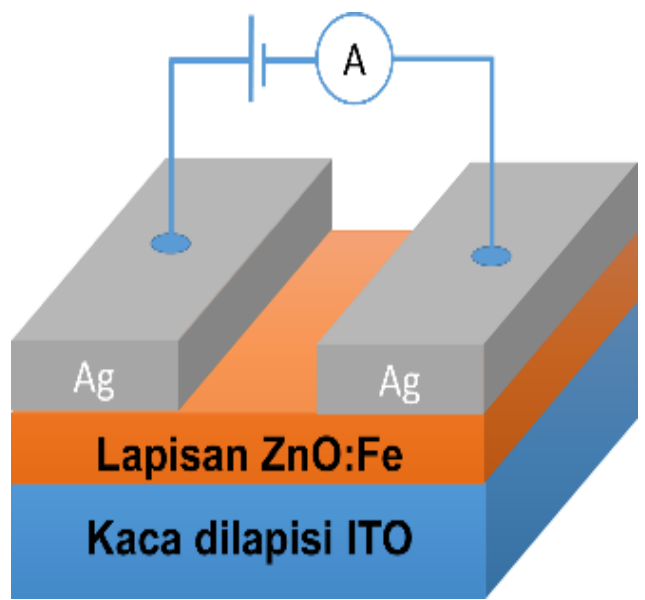

Gambar 1. Skema pengukuran I-V

\section{HASIL DAN PEMBAHASAN}

Dalam penelitian ini telah dihasilkan sampel film tipis $\mathrm{ZnO}: \mathrm{Fe}$ metode spray pyrolysis sederhana dengan alat nanospray. Film tipis $\mathrm{ZnO}: \mathrm{Fe}$ dikarakterisasi untuk mengetahui struktur morfologi dan respon arus. Morfologi permukaan dilakukan dengan karakterisasi SEM. Telah dilakukan pengujian film tipis $\mathrm{ZnO}: \mathrm{Fe}$ dengan melakukan pengukuran arus versus tegangan (I-V) dengan metode dua probe untuk mendapatkan kurva I-V. Nilai tegangan divariasikan untuk mengukur arus yang mengalir pada sampel.

Karakterisasi SEM perlu dilakukan untuk mengetahui morfologi permukaan dari film tipis berupa bentuk dan ukuran butiran (partikel). Pada hasil karakterisasi SEM ini menunjukkan bentuk dan ukuran butiran yang berbeda dari tiap sampel film tipis dengan beda molaritas. Untuk mengetahui ukuran partikel yang dihasilkan tiap sampel dilakukan pengolahan menggunakan Software imageMIF sebanyak 100x pengukuran untuk masing-masing sampel.

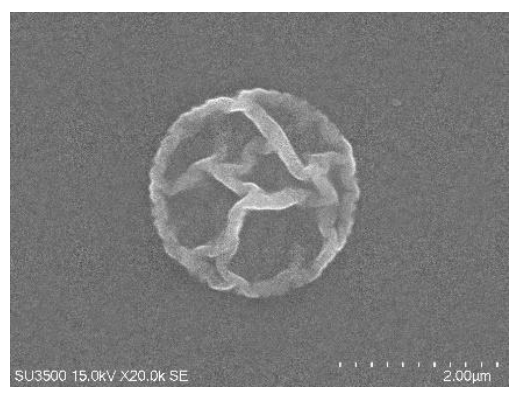

(a)

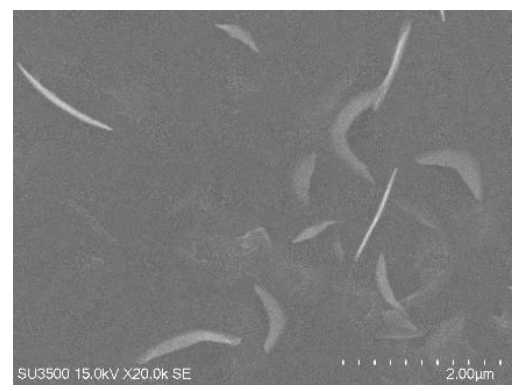

(b)

Gambar 2. Foto hasil SEM (a) $\mathrm{ZnO}$ : Fe 0,05M Etanol (b) ZnO: Fe 0,01M Etanol. 
Foto morfologi film tipis $\mathrm{ZnO}: \mathrm{Fe}$ dengan pelarut Etanol namun beda molaritas yaitu $0,05 \mathrm{M}$ dan $0,01 \mathrm{M}$ ditunjukkan pada Gambar 2. Terlihat butiran ukuran yang sangat kecil sehingga tidak terlihat jelas pada gambar SEM. Pada gambar 2.a (bentuk bulat) merupakan hasil aglomerasi dan mengakibatkan permukaan film tidak rata. Kemudian dilanjutkan dengan pengukuran ukuran partikel yang diperoleh dari pengolahan data menggunakan imageMIF menunjukkan korenpondensi hasil semakin tinggi konsentrasi prekursor, maka semakin besar ukuran partikelnya [8].

Pada hasil uji sifat listrik ditunjukkan pada Gambar 3 yang menunjukkan hasil pengukuran arus versus tegangan (I-V) menggunakan pelarut etanol dengan variasi molaritas 0,01M, 0,05M, dan 0,1M. Pada film tipis $\mathrm{ZnO}: \mathrm{Fe}$ 0,01M, 0,05M, dan 0,1M kurva I-V terlihat tidak linier. Kurva terlihat mengalami fluktuasi pada saat nilai arus gelap. Sedangkan seiring meningkatnya tegangan yang diberikan maka nilai arus terang juga terus meningkat. Didapatkannya nilai arus terang yang mulai meningkat cepat pada film tipis $\mathrm{ZnO}: \mathrm{Fe}$ etanol $0,01 \mathrm{M}$ yaitu saat mulai diberikannya tegangan pada 4 volt. Sementara pada film tipis $\mathrm{ZnO}: \mathrm{Fe}$ etanol $0,05 \mathrm{M}$ arus terang mulai meningkat cepat pada saat tegangan 5 volt. Kemudian untuk film tipis $\mathrm{ZnO}$ :Fe etanol 0,1M saat mulai diberikan tegangan 4,5 volt arus terang mulai meningkat cepat.

Dari kurva perbandingan pola terang dan pola gelap ketiga sampel terlihat bahwa arus gelap $\mathrm{ZnO}: \mathrm{Fe}$ Etanol 0,05M lebih rendah dibanding arus gelap $\mathrm{ZnO}$ :Fe Etanol 0,01M dan ZnO:Fe Etanol 0,1M. Arus gelap ketika tegangan 10 volt untuk $\mathrm{ZnO}: \mathrm{Fe}$ Etanol 0,1M adalah 1,577 $\mu \mathrm{A}, \mathrm{ZnO}: \mathrm{Fe}$ Etanol 0,1M adalah 1,366 $\mu \mathrm{A}$, dan $\mathrm{ZnO}: \mathrm{Fe}$ Etanol $0,05 \mathrm{M}$ adalah $1,193 \mu \mathrm{A}$. Arus terang $\mathrm{ZnO}: \mathrm{Fe}$ Etanol 0,05M juga lebih rendah dibandingkan arus terang $\mathrm{ZnO}: \mathrm{Fe}$ Etanol 0,01M dan ZnO:Fe Etanol 0,1M.

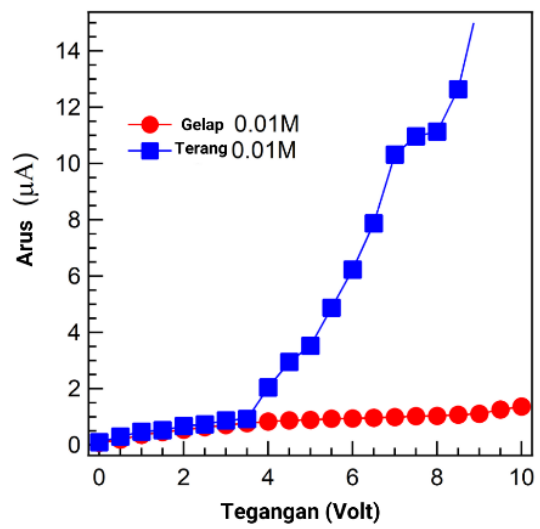

(a)

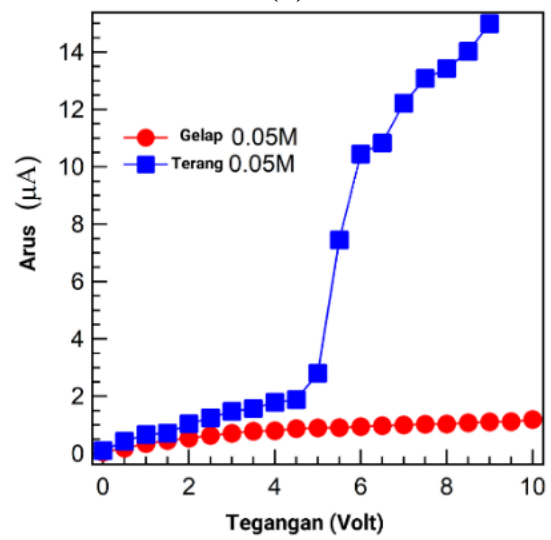

(b)

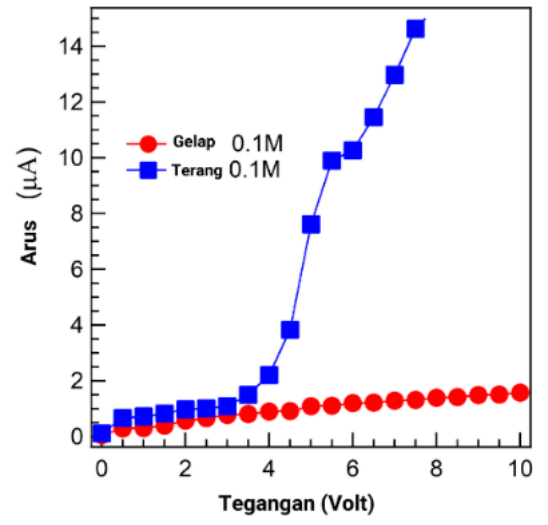

(c)

Gambar 3. Kurva I-V perbandingan molaritas film tipis FZO (a) FZO 0.01M (b) FZO 0.05M (c) FZO $0.1 \mathrm{M}$. 
Arus terang ketika tegangan 10 volt untuk ZnO:Fe Etanol 0,1M adalah 23,156 $\mu \mathrm{A}$, $\mathrm{ZnO}:$ Fe Etanol 0,01M adalah $20 \mu \mathrm{A}$, dan $\mathrm{ZnO}:$ Fe Etanol 0,05M adalah 15,931 $\mu \mathrm{A}$. Pergeseran kurva terjadi saat kondisi terang oleh lampu UV, hal tersebut dikarenakan karena daerah aktif diberi penerangan sinar UV dan membentuk pasangan elektron-hole ketika energi foton melebihi energi gap [9].

\section{KESIMPULAN}

Penumbuhan film tipis $\mathrm{ZnO}: \mathrm{Fe}$ metode spray pyrolysis dengan menggunakan alat nanospray dengan variasi molaritas telah berhasil dilakukan. Berdasarkan analisis hasil karakterisasi yang telah dilakukan, beda molaritas terhadap film tipis $\mathrm{ZnO}: \mathrm{Fe}$ dapat menurunkan ukuran partikel. ZnO:Fe 0,5M Etanol memiliki nilai respon arus tertinggi dibandingkan sampel lain karena memiliki arus gelap cukup rendah dan arus terang yang tinggi, dimana nilai sensitivitas arus pada $0.5 \mathrm{~V}$ sampel $\mathrm{ZnO}: \mathrm{Fe}$ 0,5M Etanol yaitu 2,4827 $\mu \mathrm{A}$. $\mathrm{ZnO}: \mathrm{Fe} \quad 0,5 \mathrm{M}$ berpotensi sebagai fotodetektor.

\section{UCAPAN TERIMAKASIH}

Penulis mengucapkan terima kasih kepada Kemensitekdikti atas program Hibah bantuan Penelitian Dosen Pemula Simlitabmas Tahun Anggaran 2020 Kontrak Nomor 009/SP2H/LT/DRPM/2020

\section{DAFTAR PUSTAKA}

[1] C. Aydin, M. S. Abd El-sadek, K. Zheng, I. S. Yahia, dan F. Yakuphanoglu, "Synthesis, Diffused Reflectance and Electrical properties of Nanocrystalline Fe-doped ZnO Via Sol-Gel Calcination Technique', Opt. Laser Technol., vol. 48, pp. 447452, 2013.
[2] E. Nurfani, A. Lailani, W. A. P. Kesuma, M. S. Anrokhi, G. T. M. Kadja, dan M. Rozana, "UV Sensitivity Enhancement in FeDoped ZnO Films Grown by Ultrafast Spray Pyrolysis', Opt. Mater. (Amst)., vol. 112, no. December 2020, p. $110768,2021$.

[3] E. Nurfani, G. T. M. Kadja, M. A. K. Purbayanto, dan Y. Darma, "The Role of Substrate Temperature on Defects, Electronic Transitions, and Dark Current Behavior of ZnO Films Fabricated by Spray Technique", Mater. Chem. Phys., vol. 239, no. June 2019, p. 122065, 2020.

[4] K.-S. Kim, H. W. Kim, dan C. M. Lee, "Effect of Growth Temperature on $\mathrm{ZnO}$ Thin Film Deposited on $\mathrm{SiO} 2$ Substrate', Mater. Sci. Eng. B, vol. 98, no. 2, pp. 135-139, 2003.

[5] J. B. Mooney dan S. B. Radding, "Spray Pyrolysis Processing', AnRMS, vol. 12, pp. 81-101, 1982.

[6] A. B. Khatibani dan S. M. Rozati, "Synthesis and Characterization of Amorphous Aluminum Oxide Thin Films Prepared by Spray Pyrolysis: Effects of Substrate Temperature', $J$. Non. Cryst. Solids, vol. 363, pp. 121133, 2013.

[7] G. J. Exarhos dan X.-D. Zhou, "Discovery-Based Design of Transparent Conducting Oxide Films', Thin Solid Films, vol. 515, no. 18, pp. 7025-7052, 2007.

[8] O. J. Ilegbusi, S. M. N. Khatami,dan L. I. Trakhtenberg, "Spray Pyrolysis Deposition of Single and Mixed Oxide Thin Films", Mater. Sci. Appl., vol. 8, no. 02, p. 153, 2017.

[9] S. Zhang, Electric-Field Control of Magnetization and Electronic Transport in Ferromagnetic/ Ferroelectric Heterostructures. Springer Science \& Business Media, 2014. 
Okky Fajar Tri Maryana: Pengaruh Molaritas dalam Teknik Spray terhadap Performa Fotodetektor Berbasis $\mathrm{ZnO}$ 